\title{
Monopoly as a 'culture-history fact': Knight, Menger, and the role of institutions
}

\author{
Joseph T. Salerno ${ }^{1}$ (D), Carmen Elena Dorobat ${ }^{2}$ and Matthew C. McCaffrey ${ }^{3 *}$ (D) \\ ${ }^{1}$ Economics, Lubin School of Business, Pace University, One Pace Plaza, New York 10038, USA, ${ }^{2}$ Strategic Management, \\ Manchester Metropolitan Business School SES, All Saints Campus, Oxford Road, Manchester M16 6BH, UK and \\ ${ }^{3}$ Entrepreneurship, University of Manchester, Alliance Manchester Business School, 8.047, Booth Street West, Manchester \\ M15 6PB UK \\ *Corresponding author. Email: matthew.mccaffrey@manchester.ac.uk
}

(Received 29 October 2020; revised 10 June 2021; accepted 10 June 2021)

\begin{abstract}
Frank Knight's theory of monopoly price has received relatively little attention in the literature on Risk, Uncertainty and Profit. We argue that Knight accepted and refined the monopoly price theory of Carl Menger and his followers. Knight highlights the difference between monopoly as an inevitable outcome of departures from perfect competition, and monopoly as a contingent or 'culture-history fact'. In the latter case, coercive institutional barriers to potential competition shape the choice set of consumers and producers, and provide a crucial method for identifying monopoly gains. There are three benefits to this account of Knight's contributions: it rehabilitates the focus on the institutional determinants of monopoly price, as opposed to the mainstream emphasis on market frictions and imperfections; it opens the way for a Mengerian monopoly price theory that seriously engages the study of institutions; and it adds new evidence and nuance to ongoing debates about Knight's place in economics.
\end{abstract}

Keywords: Carl Menger; Frank Knight; monopoly price

\section{Introduction ${ }^{1}$}

Monopoly price theory investigates price formation under competitive and non-competitive conditions with a view to discovering their implications for individuals, firms, markets, and public policy. It is therefore an integral part of our understanding of the pricing process in the market economy. However, mainstream economic literature discussing the fundamental aspects of monopoly has been limited in the last few decades, and few studies highlight the institutional context and institutional implications of monopoly. This oversight stems from the historical development of monopoly theory as a somewhat fragmented body of work focusing on various frictions and market imperfections that create monopoly prices, modeled as deviations from a purely theoretical benchmark such as perfect competition. In this view, institutional considerations at best take on a secondary, indirect role, limited mainly to idiosyncratic variables (Hudik and Bylund, 2021) that create or eliminate frictions or other imperfections such as transaction costs. As a result, contemporary theory neglects the direct and crucial role of both general price theory and institutions in the formation and identification of monopoly gains.

This paper explores an alternative to this type of research - one that combines causal-realist price theory with historically- and institutionally-informed analysis - by reconsidering Frank Knight's contributions on the subject of monopoly. Knight provided a mostly neglected analysis of monopoly price

\footnotetext{
${ }^{1}$ We are grateful to the editors and two anonymous reviewers for their constructive criticisms of earlier versions of the paper.

(c) The Author(s), 2021. Published by Cambridge University Press on behalf of Millennium Economics Ltd. This is an Open Access article, distributed under the terms of the Creative Commons Attribution licence (http://creativecommons.org/licenses/by/4.0/), which permits unrestricted re-use, distribution, and reproduction in any medium, provided the original work is properly cited.
} 
that directly engages with the study of institutions in order to explain 'the precise meaning of the theoretical tendencies of a private property, free exchange organization of society', and their implications, i.e. 'the conditions necessary to the realization of those tendencies' (1964: 174). Knight's analysis is rooted in both a dynamic understanding of general price theory and, equally important, an appreciation of institutional-historical barriers to market competition. As Knight sought to distil the essence of 'exchange relations' in his model of perfect competition, he was able to highlight the difference between, on the one hand, monopoly as one of several departures from the pure and unrealizable theoretical model of competition that are inevitable outcomes of the real-world 'data', and on the other, monopoly as a contingent or 'culture-history' fact. In discussing his views, we use 'institutions' to mean 'humanly devised [formal and informal] constraints that structure political, economic, and social interaction. [...] Together with the standard constraints of economics they define the choice set and therefore determine transaction and production costs and hence the profitability and feasibility of engaging in economic activity' (North, 1990: 97). The focus of Knight's (and our) discussion arises from the limitations and scope of purely economic explanations of monopoly prices; these must be complemented by understanding the role of institutions for monopoly development, in particular of 'institutions that influence the acquisition and use of coercive power' (Greif, 2005: 728), which in turn constrains market competition.

Knight's view of monopoly and competition was more nuanced than later commentators have recognized, and the way in which mainstream theory has incorporated Knight's contributions to competition has overlooked important aspects of his thought. ${ }^{2}$ In particular, Knight was averse to the view that frictions and imperfections in the market system alter in any meaningful way the causal relations that explain market price formation. He argued that,

Most of the content of economic theory must relate to lags between cause and effect, and these are not got rid of by any juggling of concepts on the pattern of acceleration in mechanics, and still less are they adequately dealt with on the pernicious analogy of "friction," which covers so many sins in economic thought (Knight, 1964: xxii; original emphasis).

Knight's originality and relevance is best framed by understanding his roots in the monopoly price tradition inspired by Carl Menger, with which Knight was fully familiar and that was at its zenith at the time of the publication of Risk, Uncertainty and Profit in 1921. The Mengerian and Knightian view stresses that it is impossible for theory to distinguish between competitive and monopoly prices under free competition, and thus to identify the presence of monopoly gains on a free market. Monopoly gains only become possible when coercion impedes or precludes potential competition. Yet this approach has since been lost amongst a multitude of studies that dissect all possible combinations of market 'frictions' or imperfections - typically compared to the benchmark of perfect competition - to understand monopoly.

A reconsideration of Knight's views on monopoly in conjunction with the Mengerians' thus highlights three important insights: first and most crucial, it can help us sketch the role of institutions in monopoly development, and can restore monopoly price theory to its original scope and relevance in economics. By reviewing Knight's analysis of monopoly, we can understand that the monopolycompetitive price distinction cannot be drawn on the abstract plane of the pure theory of exchange, but can be discovered only in the institutional facts and conditions that frame and constrain real-world

\footnotetext{
${ }^{2}$ Stigler (1957: 11) credited Knight's concept of perfect competition with 'prepar[ing] the way for the widespread reaction against it in the 1930s' through monopolistic competition theory. As we shall see, Knight's approach to competition and monopoly was not as 'austere' as Stigler claims. For Knight, 'price theory was necessary but not sufficient for our understanding of the regulation of any aspect of human conduct' (Emmett, 2009: 149). Hodgson (2001) argues that Knight was one of the greatest American institutionalists after Veblen, while Asso and Fiorito (2008: 72) contend that while Knight's writings were not a-institutional, they undermined the unity of institutionalism by rejecting 'both behaviourism and instinct-habit psychology'. For Emmett (2013: 122), Knight's view was that the 'proper science of economics sits between... institutional history and ethics'.
} 
exchanges, thus avoiding misleading concepts like market frictions or imperfections. Second, in doing this, Knight also fills a gap in the Mengerian tradition and provides an analytical foundation that genuinely engages with institutions, something critics still find lacking in Austrian work (Hodgson, 2019). Third, our discussion adds further evidence to the ongoing debate about Knight's place in the history of economics in terms of both his Austrian and institutional influences (Hudik and Bylund, 2021).

\section{Monopoly prices: potential, not perfect, competition}

Carl Menger's Principles of Economics, which Knight called 'epoch-making' in an introduction to the work (Knight, 1950), marked the beginning of a distinct tradition in monopoly price theory that was ensconced in leading American economics textbooks by World War I. ${ }^{3}$ Menger's insights on monopoly were further developed by Eugen von Böhm-Bawerk, Friedrich von Wieser, J.B. Clark, Philip Wicksteed, Herbert Davenport, Frank Fetter, and Vernon Mund. Knight was close to, and was influenced by, most of these writers and throughout his career he gravitated toward 'a Mengerian rather than a Marshallian economics' (Emmett, 2013: 5). His views resonated with Wieser's Weberian subjectivism (Yu, 2002), and he ascribed to Clark 'the methodological and theoretical focus' of his doctoral thesis - later Risk, Uncertainty and Profit (Emmett, 2020) - and an accurate articulation of 'the significance of dynamic analysis' essential for the theory of monopoly (Raines and Jung, 1988: 141). Knight also cultivated personal friendships with Davenport (at one time his doctoral supervisor), as well as with Fetter, whose emphasis on considering the individual and institutional aspects of monopoly rather than narrow technical factors like firm size and costs Knight endorsed and admired (Fetter, 1937: 97; Knight, 1937).

In fact, during his career at Chicago, Knight's general price theory remained 'closer to the Austrian' approach, whereas 'post-war Chicago School price theory was decidedly Marshallian' (Emmett, 2015: 6). Knight did have controversies with the Austrians (see Boettke and Vaughn, 2002; Cohen, 2003; Emmett, 2007), but none were fundamental methodological disagreements of the kind Knight had with his fellow Chicagoans (Emmett, 2006, 2009). ${ }^{4}$ As Yu (2002: 2) argues, 'Comparing Knight's comments on Austrian works to other non-Austrian works, it is fair to claim that Knight in general accepts the Austrian approach and is sympathetic to many of the Austrian positions.' Importantly, Knight shared many metatheoretical assumptions (Mäki, 2004) with the Mengerian causal-realist approach, ${ }^{5}$ which in turn influenced his discussion of competition and monopoly.

Mengerian monopoly price theory can be described in terms of four related and partly overlapping claims. First, monopoly price formation is governed by the general law of exchange, and does not require a separate and distinct theory. For the Mengerians, the explanation of prices under monopoly conditions is an integral component of a unified, causal-realistic theory of price. In both competitive and monopoly settings, an equilibrium price is established when the mutual benefits of exchange are exhausted, which brings about a momentary state of rest in the pricing process (Salerno, 2003). The crux of the Mengerian view was that monopoly and competitive prices were not distinguishable conceptually from the point of view of pure theory, i.e. they cannot be separated in analysis and

\footnotetext{
${ }^{3}$ See, for example, the textbooks by Henry Seager (1908), Frank Taussig (1911), Lionel Edie (1926), and Raymond Bye (1934). See also Salerno (2003, 2004). A later Mengerian, Vernon Mund (1933: 76) argued that 'Menger's logical analysis of monopoly trade was an original piece of work. Theretofore, economists had always made a distinction between the fundamental nature of monopoly price and competition price.'

${ }^{4}$ The rift with others at Chicago was due to the fact that their theories required them to 'overturn systematically the assumptions that Knight used to undergird his understanding of the relation of price theory to the defense of a free society' (Emmett, 2015: 6).

${ }^{5}$ See, for example, Knight's discussion of the 'static' versus 'stationary' state (1964: 142-143, fn.1), where he criticizes the Marshallian approach of 'arbitrary abstraction as a methodological device'. Knight seems to counter to the Marshallian approach of precisive, idealizing abstractions with a view similar to the non-precisive Aristotelian abstraction used by the Austrians (Long, 2006: 7-9), or what Mäki (2004: 322) calls 'isolation by omission'. See also Knight's similar criticisms of Marshall throughout Risk, Uncertainty and Profit (1964: 15, 71, and 166).
} 
defined in terms independent of each other and of the complex reality being studied; instead, both are explained by the theory of exchange:

[T] he general principle of all economic exchanges of goods, according to which both parties must derive an economic advantage from an exchange, maintain[s] its validity unimpaired in the case of monopoly (Menger, 1976: 211).

This differs from the mainstream exposition that has come to dominate since Menger's time, where real-world prices lie on a scale of competitiveness ${ }^{6}$ between perfect competition and monopoly, and it is the role of price theory to untangle which situations are best modelled as competitive, and which as monopolistic or oligopolistic. For instance, for Chamberlin (1949: 3-4), prices are determined by a combination of competitive and monopolistic forces, and a hybrid price theory, which combines elements of both forces, is required to distinguish the different causal relations at play. In this way, monopolistic competition theory resolved the logical inconsistencies of the Marshallian perfect competition model, inherited from Cournot and the French engineers. However, it accepted perfect competition as the ideal market situation and as the criterion for separating monopolistic and competitive prices on a free market: monopoly prices were defined in terms of competitive prices and vice versa, in the absence of other, independent criteria.

As a result, for the mainstream, monopoly prices are formed when demand is inelastic above the competitive price, i.e. when it is more inelastic than perfectly elastic demand curves under perfect competition. This benchmark compels theorists to define as monopolistic all real-world frictions, constraints, or imperfections that deviate from the unrealizable ideal of perfect competition, and that allow producers some degree of control over price or supply. These broad categories of frictions or imperfections become necessary conditions for the formation of monopoly and monopolistic prices, and capture many individual concepts, including the number of sellers, concentration or vertical integration, natural scarcity, efficiency differences, product differentiation, adjustment lags, factor immobility, transaction costs, imperfect information, bias, and many others (see e.g. Tirole, 1988: 1). These conditions are pervasive in real-world markets and in various institutional contexts, such that all market competition in this framework must inevitably lead to higher (by definition, monopolistic) prices and lower levels of output. Institutional arrangements, in this view, may operate to smooth out the imperfections and frictions that produce monopoly gains, ${ }^{7}$ but even so, 'imperfect competition equilibrium is associated with excess capacity and also loss in consumers' welfare' (Tsoulfidis, 2009: 36).

Later developments in monopoly theory remained focused on identifying the industrial conditions, under free competition, that distinguish monopoly prices by affecting the ability of producers to influence price or supply. The field of industrial organization has used these price theory principles to underpin market competition analysis, looking at how market structures dictate pricing decisions and strategic interactions for firms that face little or no competition, enabling them to increase price and reduce output (cf. Besanko et al., 2017: 167-170). This insight also underpins approaches to the firm as a governance structure, with investigations into which governance structures allow for higher efficiency and monopoly gains (Bickenbach et al., 1999; Joskow, 1991). More recent studies have looked at competitive landscapes mapped by both market and resource conditions (Peteraf and

\footnotetext{
${ }^{6} \mathrm{We}$ are grateful to an anonymous reviewer for this term.

${ }^{7}$ By the 1940s, the Chicago School rejected monopolistic competition on methodological grounds and for its impracticability for legislators (Friedman, 1953; Stigler, [1949] 1983), but proposed a return to the perfect competition model and partial equilibrium on the grounds of their predictive abilities (Tsoulfidis, 2009). The 'unrealistic' or 'unprovable' assumptions of monopolistic competition were also criticized by the proponents of the Structure-Conduct-Performance approach (Bain, 1972: 82-91; Mason, 1939). However, SCP advocates adopted as their starting point a wider definition of market structure that includes all the factors a firm considers relevant to its business policy (Monteiro and Foss, 2018). Dixit and Stiglitz (1977) reiterated in a formalized mathematical model all of Chamberlin's earlier insights, bringing about a second monopolistic competition revolution that gained particular acceptance in international trade and economic geography.
} 
Bergen, 2003), in which 'demand-side (i.e. consumer need) and supply-side (i.e. capability equivalence) elements' are combined (Monteiro and Foss, 2018) to illuminate the distinction between monopoly and competition.

However, for the Mengerians, the market demand curve is the key factor in determining the possibility of monopoly gains. This second claim underscores the fact that free competition (or what Menger called 'true competition') does not require the existence of a multitude of competitors, each of which confronts a perfectly elastic demand curve, or some other kind of idealized market conditions (Menger, 1976: 223-224). All competitors face negatively-sloped demand curves and possess the 'market power' to increase price by restricting their own supply, and economic calculation reveals to monopolist and competitor alike the price that conforms to their maximum total revenue or profit. However, the distinguishing insight is that under free competition, producers are precluded from increasing prices by restricting supply. This is because under free competition demand curves are far more elastic for competitors than for the monopolist above the price that is consistent with the sale of the entire stock of the good available, or with the complete utilization of a specific factor necessary for the production of the good, as the case may be.

Therefore, a monopolist is not completely unrestricted in influencing the course of economic events': he cannot choose to sell a particular quantity of the good and then 'fix the price at will'; nor can he fix the price and then determine the quantity of the good that will be sold on the market (Menger, 1976: 211). What does give the monopolist 'an exceptional position in economic life' is his ability to choose between setting a fixed price and selling a given quantity 'without regard to other economizing individuals' (Menger, 1976: 211). This choice means the monopolist possesses the power to increase his economic gain by restricting supply, either by destroying some of the monopolized good already in existence, or by destroying or leaving unutilized some of the productive resources under his control.

However, Mengerian analysis shows that the ability to restrict supply on a free market by withholding a portion of the stock of a good already produced cannot serve as a criterion for distinguishing a monopoly from a competitive price, because in the real world of uncertainty all entrepreneurs can resort to this tactic whenever their estimations of future demand prove incorrect (Salerno, 2004: 82). Nor can monopoly be defined as control over the price and quantity at which the exchange takes places, as all entrepreneurs have control over the quantity they produce and over the price they 'attempt' to obtain (Rothbard, 2009: 662). The Mengerians thus argued that abstract pure theory cannot establish any effective criterion for dividing the free-market price into competitive and monopolistic elements. Aspects like market frictions, the number and size of firms, product differentiation, locational advantages, and so on, may enter into an entrepreneur's estimates of the demand curve, and may help explain why a particular price is higher or lower, or why a larger or smaller quantity is sold. However, they cannot serve as guides for distinguishing between competitive or monopolistic prices, as they do not establish a conceptually different market price that could be identified as such by pure theory or even by entrepreneurs themselves (Rothbard, 2009: 699).

Third, following on from these two claims, the Mengerians highlighted the importance of potential competition in precluding monopolistic gains on the free market. Although monopoly power in the purely theoretical sense pervades the market economy that deviates from perfect competition, it does not shield the 'monopolist' from the ever-present force of actual and potential competition or, more precisely, substitution. Menger argued that 'the need for competition itself calls forth competition, provided there are no social or other barriers in the way.' This potential competition, which stems from both inside and outside the industry, as well as pervasive substitutability between industries, acts 'to keep elasticity of demand for the single producer's good extremely elastic' (Mund, 1933: 122). Mund (1933: 76) further observed that 'all prices are determined by subjective valuation, and that the effect of competition is only to call forth a different supply or a different set of prices.' For Clark (1907: 381), potential competition was a living and inescapable force in history, for, 'Since the first trusts were formed the efficiency of potential competition has been so constantly displayed that there is no danger that this regulator of prices will ever be disregarded.' 
Contrary to Clark's optimism, this point was not fully appreciated in other monopoly theorizing, which in turn had a notable influence on the way monopoly price theory was done. Mainstream discussion became focused on idealized market conditions, and on firms and markets treated in isolation, which abstracts away from the fact that the economy is a system of interrelated markets and prices. This abstraction is a methodological device (Knight, 1964: 143), yet it deliberately obscures the roles of potential competition from outside the industry and substitutability across industries in precluding the formation of a monopoly. In the mainstream, monopolistic prices are formed because frictions and imperfections do not allow for substitutability to occur as smoothly as it would under perfectly competitive conditions. Thus, factor mobility conditions, natural scarcity, efficiency differences, and product uniqueness are deterministic causes of monopolistic prices. For the Mengerians, however, all prices formed in dynamic markets, with firms as rivalrous potential competitors facing downward-sloping demand curves, are competitive prices (or 'free competition prices', in Knight's words). The presence of potential competition within and outside the industry ensures that the elasticity of demand, voluntarily determined by consumers, prevents firms from obtaining monopoly gains.

In developing the three arguments discussed above, Menger thus drew an institutional distinction between monopoly 'as an actual condition' and monopoly 'as a social restriction on free competition' (Menger, 1976: 217). The former is a trivial sense of monopoly such as a sole producer, or what Mund (1933: 115) called 'formal monopoly', devoid of monopoly gains because potential competition acts as actual competition. Monopoly in the sense of social restriction, however, can be designated as 'true monopoly' (Mund, 1933: 115): in this case, potential competition is impeded or precluded and monopoly gains made feasible, depending on specific institutional constraints and on the specific circumstances of time and place. Thus, the fourth and final claim of Mengerian monopoly price theory is that under conditions of free competition, the distinction between monopolistic and competitive prices carries little or no meaning; instead, monopoly price takes on significance in the case of barriers to potential competition. Menger reinforced this thesis in the two concrete historical examples of monopoly supply restriction he provided (Menger, 1976: 214-215): both the Dutch East India Company and the medieval guilds were founded on legal barriers to competition, and were not examples of monopoly as an actual condition. This important distinction is lost in modern monopoly analyses where monopoly gains are possible in all real-world market situations that deviate from the ideal of perfect competition.

However, Mengerians did not explore this fourth insight sufficiently - at least not until the later works of Ludwig von Mises and Murray Rothbard. The bulk of Mengerian writings in the 1920s and 30s, for example, focused on public policy issues and questions of regulatory reform, particularly issues that were inconsistent with and irrelevant for their own theory - including the concentration of ownership, cutthroat competition, and price discrimination, especially through the basing-point system of delivered prices (Salerno, 2004). In consequence, they sometimes failed to apply Menger's insight identifying monopoly as social restriction on free competition. ${ }^{8}$

Distinguishing between competitive and monopoly price remained a primary task in monopoly theory and policy. Yet the focus on frictions, technological or scarcity constraints, and other market imperfections shifted discussion away from the insights of general price theory and from the role of institutional barriers to potential competition. This latter point and its ramifications for monopoly analysis were insufficiently developed even within the Mengerian tradition. Nonetheless, the claim that barriers to free competition are the realistic, historical-institutional criterion for identifying monopoly prices was a key thread underpinning Knight's contribution to the theory of monopoly.

\section{Knight's conception of monopoly}

Since the 1980s, Knight's distinction between risk and uncertainty has been increasingly influential in fields like entrepreneurship studies (Foss and Klein, 2012, 2015; Hallberg, 2015). Yet his explanation of

\footnotetext{
${ }^{8}$ Fetter and Mund (1941) found themselves combatting the newer theory with political and policy objections rather than on theoretical terms. Fetter considered the Sherman Act to be the sum of all wisdom on antitrust policy, and put his faith in the Federal Trade Commission to enforce it.
} 
exchange and perfect competition received the most attention in the earlier general economics literature (see Emmett, 2020). However, Knight's approach to monopoly (as such) has received scant attention (Raines and Jung, 1988), and is seen as more of a 'tangent' to his more important contributions (Brooke, 2010: 230). A reason for this might be that Knight never developed 'a rigorous model of monopoly... like his model of perfect competition' (Raines and Jung, 1988: 140): perhaps Knight's 'aversion to static models' and his fear of social reformers misusing the theory 'prevented him from developing a formal monopoly model'. Knight's reticence could also be explained by his familiarity with the theory of monopoly price elaborated by Menger's followers, which enjoyed broader recognition $^{9}$ when Knight addressed the issue of monopoly in the 1920s. This may have further discouraged him from fully developing his own monopoly theory in Risk, Uncertainty and Profit, where it is used primarily as a heuristic foil for perfect competition.

However, Knight's analysis of monopoly merits closer consideration. Like most American economists of his era, he was no doubt familiar with and influenced by the long decades of debate about monopolies, trusts, and combinations that had dominated public discourse since the latter part of the 19th century. Yet Knight also clarified and expanded key insights of the Mengerians regarding the problematic distinction between competitive and monopoly price in a way that carries important implications for modern work. As we show below, Knight supported his discussion of monopoly using the first two Mengerian claims discussed above, i.e. that monopoly price formation is part of the general law of exchange, and that the demand curve is the key factor in determining monopoly price. To this, however, Knight added a more fully-fledged institutional approach to the third and fourth claims, emphasizing the role of coercion in identifying monopoly gains in real-world markets, and providing an analysis of monopoly as a concrete or 'culture-history' phenomenon based on institutional factors.

Knight deals with monopoly in chapter 6 of Risk, Uncertainty and Profit (1964: 174-194) only after he has discussed other 'imperfections' in the market such as factor indivisibilities, neighborhood effects, the interdependence of utility functions, and predatory activities. He argues that monopoly is just one of several cases in which the 'facts of ordinary life' imperfectly correspond to the ideal of perfect competition, arguing that 'the limitations of the general principles developed... must be supplemented by detailed, empirical data before completely applicable conclusions can be drawn' (Knight, 1964: 174). ${ }^{10}$

Knight accepts the usual definition of monopoly as 'the control of the supply of a commodity', but warns against the classical economists' 'confusion of control with natural limitation of supply' (Knight, 1964: 184-186). His main point is that 'the monopoly of a consumption good' may be viewed either as 'a separate productive element', an independent part of business capital and salable on the market; or, if not physically separable from the production process, as conferring 'superior productivity' and a differential rent on 'the agencies producing [the good], above physically identical agencies in other uses' (Knight, 1964: 186). Knight then extends his discussion from consumption to production, analyzing the related cases of 'exclusive control' of the supply of a factor and of a method of production (Knight, 1964: 186-190). He contends that the incentive to acquire either kind of monopoly is the power it gives 'to restrict the supply of some consumption good'. Thus, for him, 'monopoly is impossible except on the basis of some control over an element essential in the production of a commodity' (Knight, 1964: 189). Second, regarding income distribution, 'the extra product is rightly imputed to

\footnotetext{
${ }^{9}$ Taussig's textbook (1911) was widely used in universities through the 1920s in the US, and expounded the Mengerian theory of monopoly price. Knight's most developed analysis of monopoly ([1933] 1965: 90-95) provides ample support for this conjecture.

${ }^{10}$ Knight uses perfect competition in discussing monopoly only as an auxiliary construct to contrast and illuminate the workings of the market economy, not as a premise from which to deduce a theory of monopoly. In a critique of monopolistic competition models, he explains that 'the relation between perfect and imperfect competition is essentially the relation between theory and reality or practice in economics, or more accurately between the more general theory and theory in a form applicable to reality' (Knight, 1939: 361). In this he again uses methods of abstraction similar to the Mengerians, and different from more mainstream theory (cf. Long, 2006).
} 
this essential element, or to the condition that makes control possible, if separable from the rest of the situation.'

In The Economic Organization, Knight identifies 'the crux of the matter' regarding monopoly and competition as 'the degree of distinction' between goods sold by different producers (Knight, [1933] 1965: 91). Every seller possesses a monopoly of his own identity and the name under which he sells his good; in most markets, especially markets for consumer's goods, buyers are not indifferent to the unique identities of the sellers and/or the trade names of their products and differentiate between goods on this basis. These data, in conjunction with entrenched 'convention and habit' and widespread 'complementarity' between expensive and cheap products, imply that the demand for almost all products is less than perfectly elastic. For Knight though, this is nothing more than a departure from perfect competition that gives the producer 'more or less freedom in setting a price'. But despite Ford Motor Company's 'monopoly' of Ford cars and Ivory's 'monopoly' of Ivory soap, potential competition is at work in precluding a monopoly gain, as '[e]ither certainly faces real competition from other cars and other soaps' (Knight, [1933] 1965: 91; emphasis added).

Further, Knight perceptively points out that 'competition' among similar products whose inclusion under a common name is the result of historical accident, e.g. 'cars' or 'soaps', is actually a partial manifestation of the more general phenomenon of 'substitution' among all products (Knight, [1933] 1965: 91). It is in the latter sense that competition is 'universal; every commodity has substitutes, in some sense'. 'Perfect substitution' is for Knight simply another name for 'perfect competition', because in the real world, almost every producer offers for sale a unique product amidst a plethora of more or less close substitutes. Knight, like the Mengerians, views the economy as a system of interrelated markets and prices that form a larger means-ends framework, where 'all competition between products should be regarded as substitution' (Knight, 1939: 361, fn.1). Therefore, the range of substitution for a given product ultimately encompasses all the commodities in the economy because 'they all compete with each other for the consumer's money'. As opposed to perfect competition then, 'perfect monopoly' can mean only an impossible situation of no substitution whatsoever: 'Such a monopolist would have to be a pharaoh, combining ownership of his subjects and all their effects with absolute political sovereignty; in effect, he would have to be "God"' (Knight, 1939: 362). So, for Knight, 'a degree of monopoly, with competition through substitution, [is] the most common situation' (Knight, [1933] 1965: 90-91).

Knight discussed two varieties of monopoly that depart from perfect competition: (1) a market 'corner' that achieves temporary control of the existing stock of a good, and (2) 'the use of trademarks, trade names or advertising slogans' in addition to 'services of professional men with established reputations'. Knight explains that this monopoly in the purely theoretical sense pervades the market economy and is indistinguishable from free competition, as the power to extract a monopoly gain in these cases is kept in check by potential competition: 'every monopoly obviously has competition' (Knight, 1946: 85), that is, 'competition with other makes or brands is a case of substitution of more or less similar goods, such as a monopolist always has to take into account' (Knight, 1964: 186). Knight assigned equally little importance to natural monopoly (Knight, [1933] 1965: 93), and did not even mention it in Risk, Uncertainty and Profit, associating it with public utilities that required large, fixed investments whose duplication would result in waste. Rather than systematic results of unfair (or un-free) competition, these are natural occurrences under free competition due to pervasive frictions, imperfections, and other ubiquitous constraints in the market economy.

The pervasiveness of substitution, albeit imperfect in the presence of constraints and frictions, leads Knight to conclude that elasticity of demand is 'the test and measure' of the degree of monopoly power, that is, of 'the ability to fix price' in the real economy (Knight, [1933] 1965: 91). Knight thus explicitly excludes deviation from the ideal of perfect competition as a necessary or sufficient condition for the emergence of monopoly prices. His argument (Knight, 1933 [1965]: 91) implies that a sufficiently - though not necessarily perfectly - elastic demand curve above the free-market price will render restriction of supply ineffective even in the presence of imperfections or frictions that can act as natural barriers to entry. His analysis harks back to Menger, showing that if the monopolist's demand 
curve is so elastic above the free-market price that total revenue falls more rapidly than total cost as price increases, it will not profit the monopolist to restrict supply. Thus for Knight, as for the Mengerians, monopoly is an exchange phenomenon, and monopoly theory concerns price formation in an 'imperfect', that is, a real market where practically all firms face downward-sloping demand curves and potential competition in the presence of all-pervasive frictions.

The attainment of a monopoly gain, for Knight, then depends crucially upon the presence of potential competition, and on the elasticity of the demand curve for the firm's product. Knight incisively encapsulates this view in a critical and prescient remark, a précis of the Mengerian theory of monopoly price:

Whether the owner of the part of a supply can gain by withholding some of that part from use will depend upon the fraction of the supply which he holds and on the flexibility of the supply obtainable from competing sources [i.e. potential competition] and the elasticity of the demand for the product (Knight, 1964: 193, fn.1).

Knight reaches the same conclusion as Menger: as far as general exchange theory is concerned, '[n]o line can be drawn between monopoly and competition' (Knight, [1933] 1965: 91). Furthermore, if '[u] nder monopoly as under competition, the price depends upon the amount produced and marketed, and the only way in which the monopolist can control price is by limiting the supply' (Knight, [1933] 1965: 95), this leads to the conclusion that price theory cannot identify or discern 'competitive prices' from 'monopoly prices' on the free market, where 'all profit is monopoly profit' (Knight, 1939: 363). Knight (1964: 184) acknowledged specifically that 'all income, from the distributive standpoint, is dependent on the scarcity of the agents which produce it, and all in exactly the same way.' Therefore, describing income derived from the scarcity of a productive element as a 'monopoly return' is mere 'meaninglessness'. He added: 'There is under free competition no other sort of income, qualitatively or quantitatively, and the designation [i.e. monopoly return] neither distinguishes or in any significant way describes anything' under these conditions (Knight, 1964: 184; emphasis added).

Nonetheless, even in a dynamic world in which 'all commodities compete with each other for the consumer's money', Knight's further contribution lies in distinguishing a monopoly price from a free competition price by identifying the institutional-historical barriers likely to lead to the emergence of the former out of the roiling sea of substitutive competition (Knight, [1933] 1965: 91). Knight argues, like Menger, that an enterprise is 'thought of as a monopoly if 'it is in a position to charge a price above that at which other persons could do so if not prevented by some special barrier' (Knight, [1933] 1965: 91; emphasis added). These special barriers may create monopoly in a non-trivial sense: unlike inherent given conditions that create market imperfections, barriers can restrict potential competition and make monopoly gains feasible. These are, for Knight, socially devised institutional constraints that alter the economic interactions between consumers and producers by preventing voluntary exchanges, precluding potential competition and coercively reducing the elasticity of the demand curve.

Knight identifies two further varieties of monopoly thus different from those discussed above: first, 'an exclusive legal right to produce or sell a certain commodity', as exemplified in a 'patented article of consumption', which Knight links to the original meaning of monopoly as a legal concept, or 'legal' monopoly. He dedicates a lengthy discussion to patents, in which he casts doubt on the viability and fairness of such privileges; on the one hand, he sees patents on original ideas and production processes as providing 'the incentive to experimentation and development' (Knight, 1999: 200). On the other, he sees it as 'a matter of political development to provide a better way of rewarding these services than a temporary monopoly of their use' (Knight, 1964: 188). While Knight refrains from offering a categorical verdict on the welfare implications of patent grants, he does treat it in his analysis closely together with the second variety of monopoly, i.e. other forms of 'unfair competition... based on mere financial power', because they facilitate 'the threat of local underselling, boycott', and so on. Even though not formally sanctioned by the state, such threats and machinations by private firms are coercive 
infringements of property rights. Knight equates them with 'a voice in the control of property owned by others or their persons as well; that is, to part ownership' (Knight, 1964: 185).

From this, he draws a sharp institutional distinction between prices under free competition, and prices under monopoly as follows:

Free competition, of course, involves the complete, separate ownership of every productive agent or natural unit, and the exploitation of every one in a way to secure its maximum value yield. Any sort of violent interference with competition manifestly contradicts this assumption and may be roughly designated monopoly (Knight, 1964: 185; emphasis added).

Knight provides several examples of cases of violent interference with free competition across his works, including unions and agricultural cartels, and political rent-seeking by business. ${ }^{11}$ After the institutional realities surrounding regulation had changed radically under the New Deal, Knight further focused on the anti-competitive and mis-allocational effects of monopoly created by coercive legal barriers or other legal-institutional measures. Knight explains that '[p]opular criticism with respect to monopoly is, indeed, much exaggerated and misconceived. Most monopolies are in fact relatively temporary. Yet monopoly is certainly a real evil in many cases and presents a very difficult problem' (Knight, 1946: 85).

This 'very difficult problem' of monopoly Knight identifies as the result of coercive public action restricting potential competition, and not as a simple departure from perfect competition such as a downward-sloping demand curve. In this, Knight contrasts 'the mechanical imperfections of the market economy, the real ones', like frictions or natural constraints, with those 'created by stupid or unwise public action', which allow business interests to become 'far more dangerous to free society through political action as a pressure group' (Knight, 1999: 380). We expand on this distinction in the next section.

\section{Coercive institutions and monopoly development}

Hudik and Bylund (2021: 1) argue that Knight 'advocated a "middle way" between theoretical and historicist approaches to economics' and thus struck a successful balance between economic principles and historical specificity insufficiently appreciated in either Chicagoan, Austrian, or institutionalist approaches so far. Our analysis of Knight's approach to monopoly confirms this view by highlighting Knight's search for institutional history as an indispensable link between ideal economic theory and the concrete, complex reality to be explained.

In this endeavor, Knight was again in agreement with Menger. Menger's 'historical point of view' (1963: 79) sought to define how to apply economic theory to the multifaceted reality of economic life (Garrouste, 1994), while Knight argued that the economic data that fill the formal categories of pure theory must be drawn from institutional history, where 'all such things, in common with the impersonal system of market relations itself, are obviously culture-history facts and products' (Knight, 1964: xii; emphasis added). It is therefore unsurprising that Knight, to use Emmett's words, urged economists to 'simply accept the reconstituted economic theory of Menger and Knight, despite its limitations' (Emmett, 2013: 122). Knight's method of balancing pure theory and institutional history carries important implications for research in both fields.

As we have seen above, Knight and the Mengerians held the view that the distinction between monopoly and competitive prices cannot be independently established through pure theory, as 'we have no way of independently defining the "competitive price" as different from the free market price' (Rothbard, 2009: 697). However, Knight's analysis developed further the nuance of the Mengerian

\footnotetext{
${ }^{11}$ Knight's examples of violence should not be taken to mean that he thought all unions or cartels were inherently coercive: his opinion seems to be based rather on practical cases of violence that he observed. We are grateful to an anonymous reviewer for highlighting this distinction.
} 
view: economic explanations of monopoly prices must be complemented by understanding the role of institutions in monopoly development. Thus Knight filled a lacuna in the Mengerian approach by demonstrating that the monopoly-competitive price distinction can be discovered only in the institutional facts and conditions that frame and constrain real-world exchanges. ${ }^{12}$

Coercion is defined in this context as violent interference with person or property, or the threat thereof, whereas free competition obtains when personal and property rights are respected and enforced (Méra, 2010; see also, Rothbard, 2009: 84-102). Knight perceived a direct connection between monopoly and coercion, and attributed to the latter a definitional role in explaining monopoly. For example, Knight follows up a detailed discussion of legal and private coercion (1999: 15-16) with an analysis of monopoly. In this, he uses the classical definition of monopoly as 'a form of coercive power, and inadmissible in a "free" state'. Knight's insight is that the critical factor necessary to explain the creation of monopoly and monopoly gain is a change in institutional conditions from free competition to violent interference with competition, either through monopoly grants and privileges, or private coercion. These conditions make control over an essential element in production possible, and thus monopoly gains as well. Violent interference with potential competition may render demand curves inelastic above the market price, shaping the choice set for firms and the feasibility of monopoly pricing because consumers are prevented from substituting, through voluntary exchange, products from other potential competitors (Rothbard, 2009: 904).

Unlike more mainstream views of monopoly, this provides an independent theoretical distinction between a free-market price and a monopoly price, and is the Knightian condition, 'separable from the rest of the situation' that makes control of supply and thus monopoly gains possible (Knight, 1964: 189). In contrast, frictions or imperfections in the market economy, which form the basis of other monopoly price theories, are inseparable from the complex reality to be explained. At best, they can contribute to explaining how different sets of (competitive) prices are formed through entrepreneurial decisions in the absence of coercion. But under free competition, demand curves are always elastic above the market price due to potential competition, so a distinction between competitive and monopoly price under these conditions (perfect or imperfect) is spurious. In this, the MengerKnight approach also satisfies the demand of SCP theory for realism and observability. While the shape and position of real demand and cost curves is not ascertainable (Mason, 1939), the use of coercion in the market, especially through grants of legal privilege, is observable, and can serve as the basis of a monopoly price and a (broader) welfare analysis (Armentano, 1988; Rothbard, 1956). ${ }^{13}$

In the context of modern liberal democracies, coercive interference with free competition occurs most commonly through the creation of political barriers to competition (such as monopoly grants) and through regulatory privileges that favor some firms over others. The power to create such barriers is possessed mainly by states, and is enacted through legislative and regulatory bodies at all levels of government, often through legal property rights (Barzel, 1994, 1997). Coercive barriers can restrict potential competition, possibly calling forth a monopoly price. Therefore, in practice, the ability to reap monopoly gains depends crucially on the institutional environment and on the size and scope of institutions such as states. While other factors such as frictions or imperfections might lead to different demand elasticities under free competition, these are not of a monopolistic character as long as the institutional context involves buyers and sellers negotiating prices voluntarily in the absence of coercion. When coercion is absent, prices are 'competitively' determined in the sense that potential competition exists and acts as actual competition, and offers are made and rejected as consumers and producers see fit. Drawing a distinction between competition and monopoly in this context is

\footnotetext{
${ }^{12}$ Although Knight does not dwell on the historical details, his practical approach to monopoly price was likely informed by decades of debate in the United States over monopoly, competition, and antitrust policy, in addition to his theoretical views. We are grateful to an anonymous reviewer for suggesting this possibility.

${ }^{13}$ To some extent, the focus on coercion anticipated later contributions, such as Barzel's (1994) view that a monopoly position implies an economic right to do harm to others, though his view of what constitutes harm differs from the view advanced in more recent Mengerian literature, e.g. Rothbard (2009) and Salerno (2004). The scope of monopoly pricing will depend on what counts as coerced change to demand curves.
} 
not merely a definitional issue, but a Nirvana fallacy: it implies comparing 'imperfect' prices due to frictions and imperfections with impossible, 'perfectly competitive' prices with no frictions (Foss and Klein, 2012: 56, 64, fn.16, 141-142). ${ }^{14}$

More importantly, while demand elasticity is lower in the presence of coercion than under free competition, pure economic theory cannot determine whether this will inevitably lead to monopoly gains. Only 'concrete historical data' can show whether the decrease in demand elasticity has rendered the firm's demand curve sufficiently less elastic above the free competition price (Rothbard, 2009: 904). On the one hand, coercion through legal privileges reduces consumer choice (such as in the case of protective trade barriers), but may not bring a monopoly gain to the firm if it does not constrain choice sufficiently to render the demand curve inelastic and thus enable the firm to extract a higher gross revenue at a price higher than the free competition price. In some cases where potential competition is impeded, but not absolutely precluded (e.g. trade barriers), business in possession of such privileges may choose not to lower output or increase price. At the same time, if labor unions are coercive, then coercion is necessarily restrictive in terms of the total supply of labor on the market, precluding potential competition and bringing about a higher price than the free competition price, and thus a monopoly gain. Knight's understanding of potential competition made him aware of these nuances. For example, he was critical of the classical economists who 'thought that protective [trade] duties create monopoly' (Knight, 1999: 452, fn.11), hastening to add that they only 'facilitate it' instead of deterministically causing it. At the same time, he was quick to point out that 'where monopoly really bites is in the real brigandage of organized wage-earners and farmers... anything like nation-wide collective bargaining and striking is coercion of the country' (Knight, 1999: 380).

Note too that the gain accruing to a monopoly can be directly imputed to the privilege it enjoys, i.e. to the restriction on potential competition that makes control possible (Knight, 1964: 189), and then only indirectly to the monopolization of ownership of a productive asset. Monopoly gain is directly the result of a coercive privilege, and thus of the institutional context that makes privileges possible. Institutions, in this view, affect monopoly and competition directly by shaping the rules of the game, the policy menu, and the feasibility of monopoly pricing, and not by simply affecting production costs, transaction costs, or by introducing or altering frictions in the market system.

Outside the context of states, coercive power can be exercised by private institutions such as organized religions (one of Knight's favorite targets for criticism) or other influential groups, provided that their methods of governance are forceful enough. It is also possible that demand elasticity can be coercively lowered as a result of less systematic interventions, such as the use of simple force or fraud by individuals or informal groups. Once more, economic analysis alone cannot say whether these kinds of actions will necessarily result in monopoly gains, as their impact always depends on the elasticity of the demand curve for a firm above the free competition price in specific circumstances of time and place.

Whatever monopoly prices may result from these actions are also direct consequences of the institutional setting: in the case of private action, of weak institutions for contract enforcement. Historical analysis might show that such private coercion due to weak institutions is far more likely to be kept in check by potential competition as well as by the enforcement of fundamental legal institutions such as property rights. This in itself is a competitive process. In fact, Barzel argues that monopoly should be thought of as a competition over economic property rights (de facto control) to the gains from trade (Barzel, 1994: 408). Consumers have the power to raise the cost of monopoly and make it unattractive. To take only one example, 'Long-term contracts and other prior-commitments provide protection against capture by would-be monopolists by removing the opportunities for the harmful action' (Barzel, 1994: 408; also 393). Private coercion is more likely to take place outside the boundaries of

\footnotetext{
${ }^{14} \mathrm{By}$ acknowledging the universality of market frictions, the Knightian and Mengerian approach provides 'assumptional symmetry', that is, it applies the same assumptions to all actors and interactions in different domains of theory (Foss and Hallberg, 2014). This is important and necessary, as it is typically transaction costs research rather than price and production theory that includes the greatest emphasis on frictions (Langlois and Foss, 1999). The Mengerian view eliminates this imbalance.
} 
legal property rights, and therefore will not fall within the enforcement powers of states. In a sense then, this process can be thought of as a way for private individuals to resolve government failure by reallocating economic property rights and bringing them in line with legal property rights. In any case, the key point is that historical research on these cases must focus on institutions that create or eliminate monopoly gains to the extent that they allow or disallow coercive modifications of the elasticity of demand.

The previous discussion helps show the proper place of monopoly price theory that Knight envisaged: price theory can illuminate policy discussions on monopoly only insofar as to provide an understanding of how the elasticity of the demand curve is affected under different institutional contexts that may impede or preclude potential competition. It is the further task of an institutionalhistorical analysis to explain whether these conditions lead to monopoly in particular circumstances, and to inform further policy proposals. This interpretation also sheds new light on Knight's early disapproval of the 'furor' over imperfect competition:

I don't see much that can be done with it for the purposes of theory itself or its application to policy. It is always hard to say where the line is to be drawn, or the balance struck, between useful economic analysis and mere puzzle making and solving. There is a good deal of the latter in recent literature (Knight, 1939: 362).

His dismissal of such theories as 'mere puzzle making and solving' applies also to the wide body of modern research that currently informs legislators in crafting competition policy. If an analysis of frictions and imperfections under free competition cannot serve as a criterion for understanding monopoly prices, then it cannot serve as a guide for sound public policy. It is easy to see then why Knight revolted against such theories, whose 'air of revolutionary novelty... is not only false to the facts but has done great damage to our science and to the hope, already dim enough, for sound social policy' (Knight, 1939: 362).

Knight's pessimism about public policy was rooted also in his political skepticism. He mistrusted legislators' motives and doubted their competence in dealing with competition and monopoly (Raines and Jung, 1988: 139). Knight often expressed doubts about the relationship between the state and the market, and on this problem he was not so much elliptical, as unsure. He was familiar with the classical position that monopoly 'would not arise in an important degree in the absence of positive support, aid, and abetting, on the part of the state itself (Knight, 1999: 15), but he was reluctant to fully dismiss the possibility of monopoly arising and thriving purely as a result of private coercion:

This indeed is still a 'moot' question, one on which the writer has no very positive opinions, but on the issue of which he is by no means so optimistic as, for example, Professor von Mises, and Professor Robbins... However, it must be admitted that governments have never given the original liberal position any fair trial, and do not seem in a way to do so, in the visible future (Knight, 1999: 16).

At the same time, he was also unconvinced that political coercion, even limited to corrective action by governments (or what he called 'coercive repression'), could be effective in limiting the influence of private interference with free competition, warning that reformers take 'for granted that... wherever freedom yields results regarded as undesirable it should be abolished and bureaucratic control substituted in its place' (Knight, 1939: 366, fn.6). In fact, Knight's analysis of monopoly shows not only that modern theories focusing on frictions and imperfections as determinants of monopoly price fail to provide a solid rationale for policy interventions, but often bring about ambiguous results, calling for coercion to resolve market imperfections, or economize on the costs arising from frictions. His approach shows that coercion can have the opposite effect: instead of reducing monopoly gains, policy can lower the elasticity of demand and impede potential competition, moving the market not just further away from the unrealizable ideal of perfect competition, but further too from free competition. 


\section{Conclusion}

Knight's views on monopoly highlight three insights that are worth rehabilitating: first, institutional analysis must complement economic theory in understanding the existence and development of monopoly. Pure economic theory cannot distinguish, conceptually or in reality, between competitive and monopoly prices, and 'culture-history facts' must play the central role in identifying monopoly gains. Reorienting monopoly research in this Knightian direction, overlooked so far, can help scholars avoid misleading concepts like frictions and imperfections in the search for a more meaningful theoretical basis for policy recommendations. Second, this insight carries equally important implications for the Mengerians, whose analysis of monopoly as well as other concepts might fall short when making the leap between general theory and concrete historical application of theory in specific institutional settings (Hodgson, 2019). Third, for scholars of the history of economic thought, Knight's contributions on monopoly sketch a more nuanced picture of his intellectual heritage and development, dually influenced by the Mengerian tradition and the insights gleaned from his work on institutions.

Knight remained influential in the American economics scene for some time after the later Mengerians like Fetter and Mund lost the battle over monopoly price to monopolistic competition theory. Despite his pedigree as an economic theorist, however, Knight's institutional approach to monopoly also failed to make an impact in a research landscape dominated by perfect and imperfect competition models. Now, a century on from the publication of Risk, Uncertainty and Profit, contemporary mainstream work on monopoly has few insights to offer those scholars who favor a rich institutional analysis over a narrow, abstract economic approach. Yet markets are living and breathing sets of actions, rules, and institutions, and rigorous theory must make the leap to practice (and to policy) using institutional analysis. To take only one example, at a time when antitrust policy is increasingly aggressive toward major technology firms, it is more crucial than ever to move away from perfect and imperfect competition and from analyzing isolated firms and markets and toward a causal-realist approach to understanding prices and the political-regulatory basis of real-world monopoly.

One might argue that sophisticated theoretical discussions may not withstand, in the short term, the pressure from policy circles for expediency or political gain. However, uncovering the truth and limitations of economic principles, and their indelible connection with institutions, is not a thankless task whose usefulness is judged solely by its immediate impact on policy. Like institutions, correct theory may be slow to impact policy, but that fact tarnishes neither its importantance nor the relevance of efforts to recover it from the history of economic thought.

Like Knight (1964: xxxvi), we contend that our best hope is that a few people will learn the lesson and carry it forward to another historical juncture, when the "other man," who is, after all, likewise in humanity, the lover of truth and right... may get another chance.' We hope that at the bicentennial of Risk, Uncertainty and Profit, we will be able to look back on a body of monopoly price research and policy shaped by Menger and Knight's work.

\section{References}

Armentano, D. T. (1988), 'Rothbardian Monopoly Theory and Antitrust Policy', in W. Block and L. H. Rockwell Jr. (eds.), Man, Economy and Liberty: Essays in Honor of Murray N. Rothbard, Auburn, AL: Ludwig von Mises Institute, pp. 3-11. Asso, P. F. and L. Fiorito (2008), 'Was Frank Knight an Institutionalist?', Review of Political Economy, 20(1): 59-77.

Bain, J. S. (1972), Essays on Price Theory and Industrial Organization, Boston: Little, Brown \& Co.

Barzel, Y. (1994), 'The Capture of Wealth by Monopolists and the Protection of Property Rights', International Review of Law and Economics, 14(4): 393-409.

Barzel, Y. (1997), Economic Analysis of Property Rights, Cambridge: Cambridge University Press.

Besanko, D., D. Dranove, M. Shanley and S. Schaefer (2017), Economics of Strategy (7th edn), Hoboken, NJ: John Wiley \& Sons.

Bickenbach, F., L. Kumkar and R. Soltwedel (1999), The New Institutional Economics of Antitrust and Regulation, Kiel Working Paper No. 961, Kiel: Kiel Institute of World Economics.

Boettke, P. J. and I. K. Vaughn (2002), 'Knight and the Austrians on Capital, and the Problem of Socialism', History of Political Economy, 34(1): 155-176. 
Brooke, G. (2010), 'Uncertainty, Profit and Entrepreneurial Action: Frank Knight's Contribution Reconsidered', Journal of the History of Economic Thought, 32(2): 221-235.

Bye, R. T. (1934), Principles of Economics, (3rd edn), New York: F.S. Crofts \& Co.

Chamberlin, E. H. (1949), Theory of Monopolistic Competition: A Re-Orientation of the Theory of Value, London: Oxford University Press.

Clark, J. B. (1907), Essentials of Economic Theory: As Applied to Modern Problems of Industry and Public Policy, New York: The Macmillan Company.

Cohen, A. J. (2003), 'The Hayek/Knight Capital Controversy: The Irrelevance of Roundaboutness, or Purging Processes in Time?', History of Political Economy, 35(3): 469-490.

Dixit, A. K. and J. E. Stiglitz (1977), 'Monopolistic Competition and Optimum Product Diversity', American Economic Review, 67(3): 297-308.

Edie, L. D. (1926), Economics: Principles and Problems, New York: Thomas Y. Crowell Company.

Emmett, R. B. (2006), 'De Gustibus est Disputandum: Frank H. Knight's Reply to George Stigler and Gary Becker's "De Gustibus non est Disputandum” with an Introductory Essay', Journal of Economic Methodology, 13(1): 97-111.

Emmett, R. B. (2007), 'Knight's Challenge (to Hayek): Spontaneous Order is not Enough for Governing a Liberal Society', in L. Hunt and P. McNamara (eds.), Liberalism, Conservatism, and Hayek's Idea of Spontaneous Order, New York: Palgrave Macmillan, pp. 67-86.

Emmett, R. B. (2009), 'Did the Chicago School Reject Frank Knight? Assessing Frank Knight's Place in the Chicago Economics Tradition', in R. B. Emmett (ed.), Frank Knight and the Chicago School in American Economics, London: Routledge, pp. 145-155.

Emmett, R. B. (2013), 'Frank H. Knight on Institutionalism and Economics', Research in the History of Economic Thought and Methodology, 31b: 117-124.

Emmett, R. B. (2015), 'Frank H. Knight and the Chicago School (October 5, 2015)'. ASU Center for the Study of Economic Liberty Research Paper.

Emmett, R. B. (2020), 'The Writing and Reception of Risk, Uncertainty and Profit (August 17, 2020)'. Cambridge Journal of Economics Special Issue on Frank Knight's Risk, Uncertainty and Profit \& J. M. Keynes' Treatise on Probability.

Fetter, F. A. (1937), 'Planning for Totalitarian Monopoly', Journal of Political Economy, 45(1): 95-110.

Fetter, F. A. and V. Mund (1941), 'Duopoly Theory versus Antitrust Policy.' Unpublished manuscript. Frank A. Fetter mss., 1875-1988. Lilly Library, Indiana University Bloomington, Box 9, Folder: Unpublished writings: 1898-1943 and undated.

Foss, N. J. and N. L. Hallberg (2014), 'How Symmetrical Assumptions Advance Strategic Management Research', Strategic Management Journal, 35(6): 903-913.

Foss, N. J. and P. G. Klein (2012), Organizing Entrepreneurial Judgment: A New Approach to the Firm, Cambridge: Cambridge University Press.

Foss, N. J. and P. G. Klein (2015), 'Introduction to a Forum on the Judgment-Based Approach to Entrepreneurship: Accomplishments, Challenges', New Directions. Journal of Institutional Economics, 11(3): 585-599.

Friedman, M. (1953), The Methodology of Positive Economics, Chicago: Chicago University Press.

Garrouste, P. (1994), 'Menger and Hayek on Institutions: Continuity and Discontinuity', Journal of the History of Economic Thought, 16(2): 270-291.

Greif, A. (2005), 'Commitment, Coercion, and Markets: The Nature and Dynamics of Institutions Supporting Exchange', in C. Menard and M. Shirley (eds.), Handbook of New Institutional Economics, Boston, MA: Springer, pp. 727-786.

Hallberg, N. L. (2015), 'Uncertainty, Judgment, and the Theory of the Firm', Journal of Institutional Economics, 11(3): 623-650.

Hodgson, G. M. (2001), 'Frank Knight as Institutionalist Economist', in J. E. Biddle, J. B. Davis and S.G. Medema (eds.), Economics Broadly Considered: Essays in Honor of Warren J. Samuels, London: Routledge, pp. 64-93.

Hodgson, G. M. (2019), 'Austrian Economics is Still Not Institutional Enough', Advances in Austrian Economics, 24: 101-110.

Hudik, M. and P. L. Bylund (2021), 'Let's Do It Frank's Way: General Principles and Historical Specificity in the Study of Entrepreneurship', Journal of Institutional Economics, 17: 1-16.

Joskow, P. L. (1991), 'The Role of Transaction Cost Economics in Antitrust and Public Utility Regulatory Policies', The Journal of Law, Economics and Organization, 7(Special issue): 53-83.

Knight, F. H. (1937), 'Letter to Frank A. Fetter, dated 25 February. Frank A. Fetter mss., 1875-1988.' Lilly Library, Indiana University Bloomington, Box 2, Folder: Correspondence 1937, Jan.-June.

Knight, F. H. (1939), 'Imperfect Competition', Journal of Marketing, 3(4): 360-366.

Knight, F. H. (1946), 'The Sickness of Liberal Society', Ethics, 56(2): 79-95.

Knight, F. H. (1950), 'Introduction', in J. Dingwall and B. F. Hoselitz (Tr.), Carl Menger, Principles of Economics, Glencoe, IL: Free Press, pp. 9-35.

Knight, F. H. (1964), Risk, Uncertainty and Profit, New York: Augustus M. Kelley.

Knight, F. H. (1999), Selected Essays by Frank H. Knight, Volume 2: Laissez Faire: Pro and Con, R.B. Emmett (ed.), Chicago: University of Chicago Press. 
Knight, F. H. ([1933] 1965), The Economic Organization, New York: Harper \& Row.

Langlois, R. N. and N. J. Foss (1999), 'Capabilities and Governance: The Rebirth of Production in the Theory of the Firm', KYKLOS, 52(2): 201-218.

Long, R. T. (2006), 'Realism and Abstraction in Economics: Aristotle and Mises Versus Friedman', The Quarterly Journal of Austrian Economics, 9(3): 3-23.

Mäki, U. (2004), 'Theoretical Isolation and Explanatory Progress: Transaction Cost Economics and the Dynamics of Dispute', Cambridge Journal of Economics, 28(3): 319-346.

Mason, E. S. (1939), 'Price and Production Policies of Large-Scale Enterprise', The American Economic Review, 29(1): 61-74.

Menger, C. (1963), Problems of Economics and Sociology, trans. J. Dingwell and B.F. Hoselitz, Urbana, IL: University of Illinois Press.

Menger, C. (1976), Principles of Economics, Tr. J. Dingwall and B.F. Hoselitz. New York: Institute for Humane Studies.

Méra, X. (2010), 'Factor Prices under Monopoly for Their Products', Quarterly Journal of Austrian Economics, 13(1): 48-70.

Monteiro, G. F. A. and N. Foss (2018), 'Resources and Market Definition: Rethinking the "Hypothetical Monopolist" from a Resource-Based Perspective', Managerial and Decision Economics, 39(3): 346-353.

Mund, V. A. (1933), Monopoly: A Theory and History, Princeton, NJ: Princeton University Press.

North, D. N. (1990), Institutions, Institutional Change, and Economic Performance, Cambridge: Cambridge University Press.

Peteraf, M. A. and M. E. Bergen (2003), 'Scanning Dynamic Competitive Landscapes: A Market-Based and Resource-Based Framework', Strategic Management Journal, 24(10): 1027-1041.

Raines, J. P. and C. R. Jung (1988), 'Monopolies as “Mechanical Defects”: Frank H. Knight on Market Power', Journal of the History of Economic Thought, 10(2): 135-143.

Rothbard, M. N. (1956), 'Toward a Reconstruction of Utility and Welfare Economics', in M. Senholtz (ed.), On Freedom and Free Enterprise: Essays in Honour of Ludwig von Mises, Princeton, NJ: Van Nostrand, pp. 224-262.

Rothbard, M. N. (2009), Man, Economy, and State with Power and Market, Auburn, AL: Ludwig von Mises Institute.

Salerno, J. T. (2003), The Development of the Theory of Monopoly Price: From Carl Menger to Vernon Mund, Southern Economic Association Conference, November 21-23.

Salerno, J. T. (2004), 'Menger's Theory of Monopoly Price in the Years of High Theory: The Contribution of Vernon A', Mund. Managerial Finance, 30(2): 72-92.

Seager, H. R. (1908), Introduction to Economics (3rd edn), New York: Henry Holt and Company.

Stigler, G. J. (1957), 'Perfect Competition, Historically Contemplated', Journal of Political Economy, 65(1): 1-17.

Stigler, G. J. ([1949] 1983), Monopolistic Competition in Retrospect. Reprinted in The Organization of Industry, Chicago: Chicago University Press.

Taussig, F. W. (1911), Principles of Economics, New York: Macmillan.

Tirole, J. (1988), The Theory of Industrial Organization, Cambridge, MA: MIT Press.

Tsoulfidis, L. (2009), 'The Rise and Fall of Monopolistic Competition Revolution', International Review of Economics, 56(1): 29-45.

Yu, T. F. L. (2002), 'The Economics of Frank H. Knight: An Austrian Interpretation', Forum for Social Economics, 31(2): $1-23$.

Cite this article: Salerno JT, Dorobat CE, McCaffrey MC (2021). Monopoly as a 'culture-history fact': Knight, Menger, and the role of institutions. Journal of Institutional Economics 17, 1049-1064. https://doi.org/10.1017/S1744137421000515 